\title{
Laboreal
}

Volume $9 \mathrm{~N}^{\circ} 1$ | 2013

Varia

\section{Apresentação esquemática do conceito de representação em ergonomia}

Presentación esquemática del concepto de representación en ergonomía

Présentation schématique du concept de représentation en ergonomie

Schematic outline of the representation concept used in ergonomics

\section{Catherine Teiger}

Tradutor. João Viana Jorge

\section{OpenEdition}

Journals

Edição electrónica

URL: http://journals.openedition.org/laboreal/6314

DOI: 10.4000/laboreal.6314

ISSN: 1646-5237

Editora

Universidade do Porto

\section{Refêrencia eletrónica}

Catherine Teiger, « Apresentação esquemática do conceito de representação em ergonomia »,

Laboreal [Online], Volume 9 No1 | 2013, posto online no dia 01 julho 2013, consultado o 24 setembro 2020. URL : http://journals.openedition.org/laboreal/6314 ; DOI : https://doi.org/10.4000/laboreal. 6314

Este documento foi criado de forma automática no dia 24 setembro 2020.

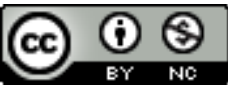

Laboreal está licenciado com uma Licença Creative Commons - Atribuição-NãoComercial 4.0 Internacional. 


\title{
Apresentação esquemática do conceito de representação em ergonomia
}

\author{
Presentación esquemática del concepto de representación en ergonomía \\ Présentation schématique du concept de représentation en ergonomie \\ Schematic outline of the representation concept used in ergonomics
}

\section{Catherine Teiger}

Tradução : João Viana Jorge

\section{REFERÊNCIA}

Texto original : Teiger, C. (1990). Présentation schématique du concept de réprésentation en ergonomie. In M. Dadoy, Cl. Henry, B. Hillau, G. De Terssac, J.-F. Troussier, A. Weill-Fassina. Les analyses du travail enjeux et formes (199-205). Paris CEREQ (Centre d'Études et de Reherches sur les Qualifications). Collection des Études n 54.

\section{Origem e papel do conceito de representação}

1 O conceito de " representação » é, há uma vintena de anos, provavelmente um dos mais expandidos e dos mais produtivos em psicologia do trabalho e em ergonomia, e ainda que certos autores prefiram o termo "modelo mental» [BAINBRIDGE (1969] a ideia maior a reter é que " um processo de tratamento não funciona diretamente sobre o real mas sobre essa representação lhe é adaptada » [BISSEREC (1970), (1971)].

2 Todavia o termo "representação " pode prestar-se a confusão porque exprime em simultâneo "o modelo interiorizado da realidade que assegura a guidage da ação » $\mathrm{e}$ também “ o processo pelo qual a pessoa constitui esse modelo ». 
O papel da representação na guidage da ação é essencial: “pela representação o operador constitui a sua informação sobre o objeto. Ela permite ao operador organizar mentalmente a solução, calcular as suas ações a partir dessa modelação interiorizada do sistema técnico. Essa representação vai permitir uma simulação mental que será um fator essencial da planificação da ação » [LEPLAT (1985)].

3 A origem do conceito de representação remonta à filosofia grega. Para Aristóteles "a ideia de objeto é o seu reflexo ideal». No fim do século XIX a psicologia geral com a escola associacionista e a escola de Würzeburg procura "identificar a natureza da imagem mental ». Essas teorias foram mantidas dormentes durante as horas de glória do behaviorismo que não se interessa senão pelas entradas e saídas do operador humano (esquema estímulo - resposta) e recusa interessar-se pelo que se passa na “ caixa negra » do cérebro.

4 É reagindo contra esta escola que, pelos anos 60, a noção de “ imagem mental » se torna objeto de uma retoma de interesse por parte de duas grandes correntes de pesquisa :

- por um lado a psicologia genética, com PIAGET [PIAGET et alii (1966)] para quem “ a imagem é uma imitação ativa e interiorizada da perceção » que aparece bastante tarde na ontogénese (pelos dois anos, sob a forma de imagens apenas "reprodutoras", depois, pelos sete - oito anos sob a forma de imagens "antecipativas»). Todavia a imagem mantém-se sempre secundária em relação às operações mentais efetuadas pelo sujeito ;

- por outro, a escola russa de psicologia e de psicofisiologia, em particular a da psicologia do trabalho com LOMOV e sobretudo OCHANINE que cria o neologismo de imagem "operativa " ao qual voltaremos.

5 Nestes últimos anos as pesquisas sobre a imagética mental e sobre as representações (e noções vizinhas) conheceram um desenvolvimento considerável devido à (é uma banalidade lembrá-lo) introdução de dispositivos automatizados e informatizados que suprimem o contato direto do operador com o objeto de trabalho e o obrigam a agir através de intermediários. A representação do sistema desempenha um papel, mais que nunca, preponderante. As pesquisas são demasiado numerosas para serem aqui citadas. Dar-se-ão alguns exemplos de entre os mais significativos a propósito das questões levantadas pela sua construção, condições de acesso, reestruturação no decurso da ação, falhas, etc.

\section{Da “ imagem operativa » à “ representação funcional »}

OCHANINE gostava de contar que a ideia de uma funcionalidade da imagem mental lhe tinha ocorrido ao constatar que os caminhos tomados pelos transeuntes para atravessar uma praça de Moscovo coberta de neve não tinham nada a ver com os trajetos geométricos desenhados pelo arquiteto. Numerosas experiências de laboratório sobre a telecondução, entre outras, e estudos sobre o trabalho, realizados nomeadamente com os dispositivos de comando de centrais térmicas, levaram-no a constatar que os operadores não se servem senão de certas informações fornecidas pelo dispositivo. Mais ainda, o esquema tecnológico, completo, da instalação atrapalha-os mais do que os ajuda.

7 Utilizam aquilo que OCHANINE designa inicialmente de esquema " psicológico », o qual põe em evidência unicamente as relações entre os elementos do sistema (circuito da 
central, por exemplo) que lhes são essenciais para executar o trabalho. Na prática este esquema, ainda que parcialmente incorreto, permite àqueles que o utilizam serem bem sucedidos, melhor e mais depressa do que os que utilizam o esquema tecnológico do engenheiro. Baseando-se em numerosas observações deste tipo, OCHANINE é levado a forjar a noção “ de imagem operativa » no sentido em que ela permite atuar :

“A ação sobre um objeto pode ser definida como um processo em que a informação sobre os estados sucessivos do objeto é transformada em ações finalizadas sobre esse objeto. Essa transformação tem lugar na sequência de uma confrontação oriunda do objeto com aquela de que o sujeito já dispõe, por exemplo a informação sobre a forma ou a estrutura do objeto, o seu estado pretendido, o algoritmo do seu funcionamento enquanto sistema dinâmico, etc. (...) Esta informação preexistente com a qual é confrontada a informação "exteroceptiva" aparece muito frequentemente organizada numa imagem operativa caracterizada antes de tudo pela sua ordenação estrutural » [OCHANINE (1969)].O que implica que " não podemos acreditar na ideia de uma imagem universal " [OCHANINE (1977)]. Afirmação com pesadas consequências teóricas e práticas, particularmente importantes para a ergonomia.

Fig. 1. Variante "psicológica"

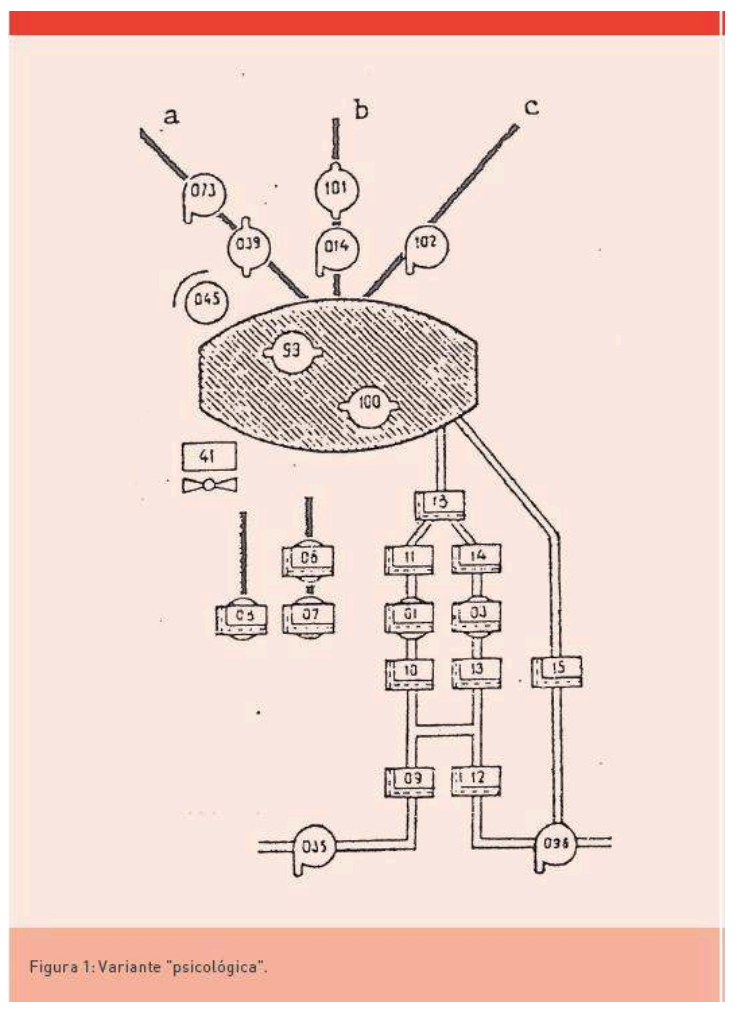




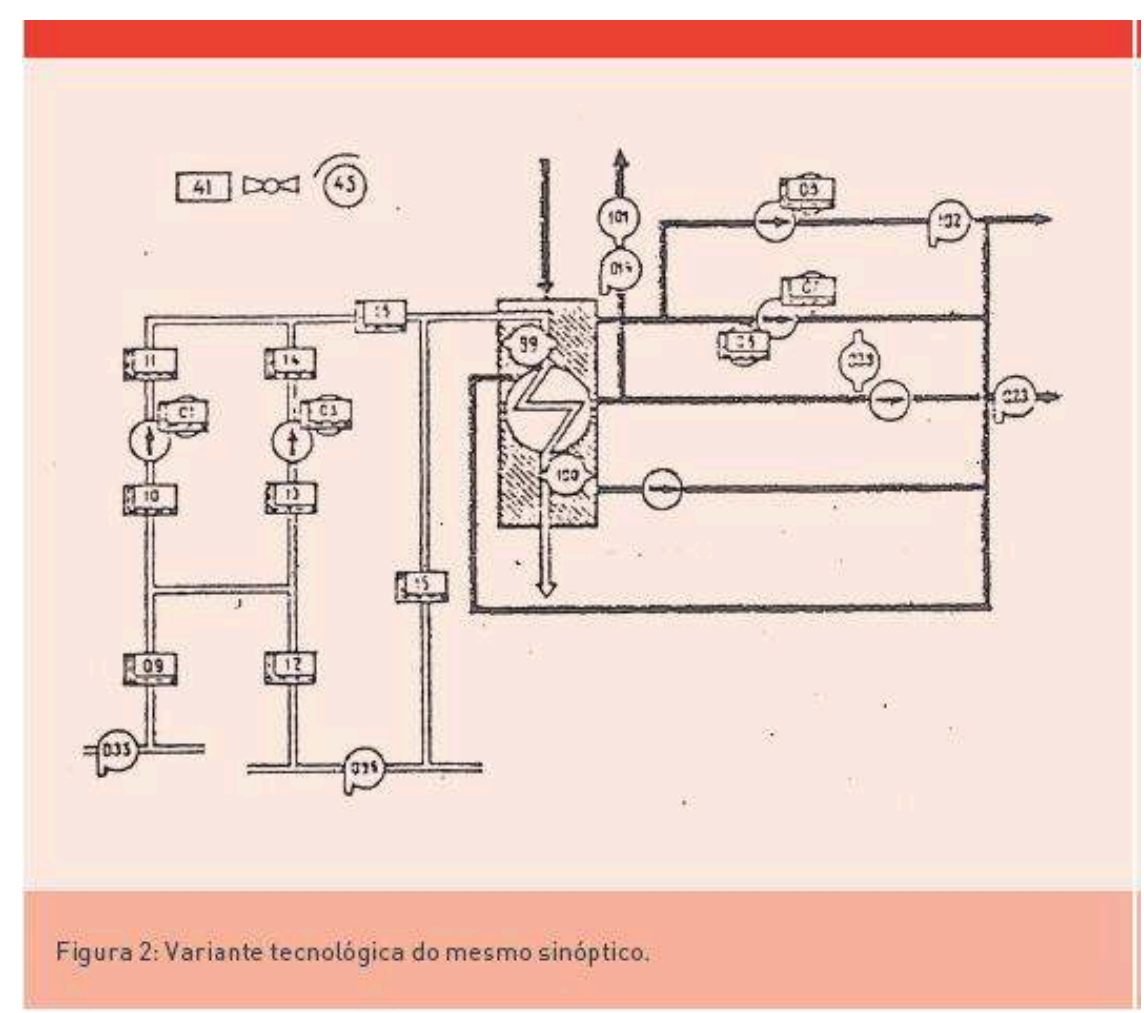

Comparemos a variante “psicológica " que nós estabelecemos para o sinóptico do circuito de óleo de uma central térmica com o sinóptico “tecnológico » deste mesmo circuito.

o que distingue fundamentalmente a nossa sinóptica da variante tecnológica é o ser baseada no princípio da integração e de diferenciação da informação/imagem pela colocação em evidência de estruturas semânticas parciais que observámos nos nossos sujeitos no momento da formação da imagem operativa. Neste caso concreto de esquema sinóptico esse princípio encontrou a sua expressão :

a. numa nítida delimitação da zona de sinalização (instrumentos indicadores 073, 039, 045, 101, $014,102,99,100$ ) e da zona de comando (válvulas $09,10,11,12,13,14,15,18$ e bombas a motor 08, 06, 07, 01, 03) ;

b. na ligação estrutural das saídas ("endereços") do grupo eletrogéneo referentes às correspondentes fontes de informação (três raios na parte superior do nosso esquema);

c. no isolamento estrutural, no interior da zona de comando, e a organização numa linha imediatamente visível das bombas de água e óleo que são os principais meios de ação na dinâmica dos fluídos tecnológicos $(08,07,01,03)$;

d. na atribuição, na representação do grupo eletrogéneo, de uma forma específica e chamativa favorecedora da localização operativa da informação que se lhe refere, na sinóptica geral da central, extremamente complicada e sobrecarregada.

Extraído de [OCHANINE (1969)].

11 As características da imagem operativa

- É finalizada pela ação. Constitui portanto “ uma estrutura informacional especializada (e não universal) que se forma no decurso de tal ou tal ação dirigida para os objetos », por oposição à “imagem cognitiva " que seria “o reflexo integral dos objetos em toda a diversidade das suas propriedades acessíveis ». 
- É seletiva e lacónica. Não retém senão o que tem valor para a ação e suprime o " ruído » informacional. “Um espetador não é um homem de ação » dizia OCHANINE, “ há demasiada informação ». Trata-se de uma outra diferença da imagem cognitiva : "o valor da imagem cognitiva consiste em ser a mais completa possível, o valor da imagem operativa é o de ser a menos obstrutiva (...). Tudo deve ser "económico": em relação à pletora da imagem cognitiva, a imagem operativa é lacónica » [OCHANINE (1969)]. O laconismo da informação retida é tanto mais acentuado quanto mais rápida deva ser a resposta.

- Está sujeita à “ deformação funcional ". “ A imagem é uma réplica deformada do objeto ", dado que a imagem operativa apresenta uma "acentuação dos pontos informativos mais importantes em função da tarefa encarada » [OCHANINE (1972)]. Deformação não significa erro mas uma hierarquização particular dos elementos da realidade pertinentes para o operador que pode parecer uma “ monstruosidade tecnológica » mas é eficaz. A deformação incide assim, tanto nos dados como nas relações entre eles, o que os estudos sobre os “ mapas mentais " demonstram: por exemplo os trajetos dos peões avaliados não pelo número de passos mas pelas atividades realizadas ao longo do trajeto [WEILL-FASSINA (1981)], ou as diferentes representações dos condutores de táxi conforme as zonas pertencem á “ rede de base » ou à “ rede secundária » que construíram com a experiência [PAILHOUS (1970)].

12 As implicações da noção de imagem operativa

- A construção pela ação e o dinamismo da imagem

13 A imagem não é a “ cópia dormente de experiências anteriores » [NEISSER (1967)], constrói-se a partir de uma exploração ativa da realidade e em função de ações sobre o objeto e de transformações do objeto consecutivas à ação.

OCHANINE insiste no carácter dinâmico da imagem operativa que é duplo dado que o operador se transforma e que o sistema de trabalho se modifica constantemente. A imagem operativa reflete em simultâneo esta dinâmica instantânea da situação e a dinâmica desejada (ela própria representação móvel das transformações esperadas pelo operador).

15 Integra assim a formação anterior, as informações “prévias " fornecidas sobre o sistema, e a experiência (acumulação do saber fazer). Em contrapartida a imagem operativa empobrece-se se pouco ou nada utilizada numa ação que a reatualize. É o problema que coloca o tratamento dos incidentes raros.

- As transformações da imagem em função da finalidade a alcançar por uma mesma tarefa

16 Um mesmo operador pode construir diversas imagens operativas do mesmo dispositivo segundo o objectivo que se propõe ou que lhe é imposto em momentos diferentes. Mas a eficácia destas imagens não é equivalente no que respeita à realização final. Uma experiência sobre o controlo de um processo cíclico variável com detecção de “ incidentes " aleatórios mostra a superioridade da instrução " parar o processo antes que o incidente intervenha " sobre a de "parar logo que o incidente surja », sendo diferentes as “ imagens operativas » e os indicadores utilizados nos dois casos [OCHANINE (1973)].

17 A maior parte das actuais pesquisas ergonómicas no terreno confirmam estes resultados : os operadores procuram sempre detectar de preferência o incidente antes ou em vias de se produzir do que depois. Desenvolvem numerosos indicadores formais e informais de alerta a fim de antecipar o incidente. É um dos problemas levantados pelas instalações informatizadas muito sofisticadas que nem sempre permitem esta 
antecipação o que é muito oneroso para os operadores (e provavelmente para a segurança do sistema!).

- A imagem varia em função da tarefa a cumprir e da função ocupada na empresa

Já se disse que o esquema "psicológico" dos operadores e o esquema tecnológico concebido ou do engenheiro nada tem a ver um com o outro. Tarefas diferentes a realizar arrastam portanto uma heterogeneidade de representações do mesmo dispositivo no seio dos membros de uma mesma empresa, sejam operadores de comando ou operadores de exterior, engenheiros, pessoal da manutenção, construtores. Os trabalhos de [RICHARD (1983)] mostraram recentemente que, no domínio da informática, a lógica de funcionamento (se comando A --- efeito B) diferia da lógica de utilização (se efeito B desejado --- comando A). Nenhuma das imagens, nenhuma das lógicas é melhor que as outras, elas são parcelares e parciais e sobretudo complementares; e estas diferenças devem ser reconhecidas e tomadas em conta na empresa sob pena de dificuldades na realização do trabalho ou mesmo de disfuncionamentos graves das instalações.

\section{Os limites da " imagem operativa " : a noção de " representação funcional "}

Ainda que reconhecendo a riqueza e a originalidade da contribuição da noção de " imagem operativa " no domínio da psicologia e no da ergonomia, alguns psicólogos do trabalho propuseram, no início dos anos 80, utilizar de aí em diante, sobretudo o conceito de "representação funcional ». Ao mesmo tempo mais preciso e mais completo do que o de "imagem operativa " permite evitar os riscos de confusão semântica e reintegrar o significado de imagem para o operador, a possibilidade de proceder a transformações da imagem e de passar de uma imagem a outra [VERMERSCH (1981); WEILL-FASSINA (1981) ; LEPLAT (1985)]. Por exemplo, a representação que vai obter-se de uma cidade vai primeiro constituir uma visão muito global, com algumas referências. Em seguida vão poder estabelecer-se itinerários, tratando-se já de uma representação estruturada da cidade. Depois vão assinalar-se (alguns) elementos e transformar essa imagem, situando-se no seu interior, sob diferentes pontos de vista, segundo o que se tem a fazer na cidade. É assim que se reintroduz a noção de “ operações na imagem ».

\section{Algumas questões colocadas atualmente pelas representações}

- A variabilidade temporal das representações. Desde há vários anos as pesquisas de cronologia em situação de trabalho põem em evidência as variações importantes dos procedimentos de trabalho em função do momento da jornada : variações ultradianas $(<24 \mathrm{~h})$ e circadianas (ligadas ao nictémero). Por exemplo, as modalidades de controlo visual de um quadro de comando são diferentes de dia ou de noite e traduzem de facto diferenças nas representações do dispositivo dos mesmos operadores em função do seu estado interno, o que tem múltiplas consequências no plano de organização do trabalho e da concepção dos dispositivos técnicos [QUEINNEC et alii (1981)].

- Os “ erros diabólicos " de representação. Trata-se aqui da problemática do “ erro humano » termo ao qual preferimos ao de "fracasso ", na esteira de [WISNER e DANIELLOU (1986)] que evita a polarização em um só indivíduo. Como quer que seja, os acidentes espectaculares dos últimos anos, nomeadamente o de Three Mile Island, implicaram tal erro de representação do sistema (a indicação de uma ordem "válvula fechada » foi tomada como indicação de 
resultado), e sobretudo como esse erro pôde persistir, que ele foi classificado de " diabólico "

(“errare humanum est, perseverare diabolicum » [CARNINO et alii (1986)].

21 Segundo aqueles autores tal erro pode situar-se ao nível dos mecanismos e dos disfuncionamentos internos do raciocínio do indivíduo ou ainda ao nível de uma interpretação inicial inexacta mal-grado os raciocínios ulteriores serem coerentes. A questão é, entre outras, a da capacidade ou incapacidade dos operadores de mobilizarem instantaneamente, no momento requerido, as representações mais operacionais para fazer face ao incidente e a dos factores que entravam essa capacidade de mobilização mesmo que disponham de conhecimentos suficientes para desempenhar a tarefa (é preciso notar, relativamente ao que se disse no ponto precedente, que na sua maioria as grandes catástrofes tiveram lugar ao princípio da manhã, à hora do " vazio » do funcionamento do organismo humano).

- Os modos de constituição das representações. Várias questões se colocam: como se elaboram as representações? Qual a articulação entre a formação inicial e a experiência? Que utensílios formais são úteis ou, pelo contrário, como é que a ausência de utensílios formais é compensada e quais as consequências para a ação ?

- As representações coletivas. Numerosas questões constituem o objetivo de pesquisas neste domínio [SAVOYANT (1981)]: as modalidades de construção de representações coletivas; como são elas utilizadas ? Que comunicações exigem ? Que modo de confrontação?

- 0 acesso às representações. Este ponto requereria igualmente e por si só todo um artigo, dado que coloca a questão dos métodos que pode utilizar um analista que detém a sua própria representação da representação de outrem: observação dos procedimentos, verbalizações provocadas ou não, imediatas ou diferidas, análise dos produtos da atividade (notas, esquemas, desenhos pessoais, “traços » diversos ...). Uma parte das contribuições deste volume aborda a questão que aqui não desenvolveremos.

- Representação funcional/representação psicoafectiva. Um último ponto que não faremos mais do que mencionar é o da articulação entre representação funcional ligada à execução prática do trabalho e representação psicoafectiva que o operador constrói da sua própria relação de trabalho. Constituiu, entre outras, o objeto de um seminário interdisciplinar cujos trabalhos foram publicados [DEJOURS et alii (1988)].

\section{Alguns domínios de aplicação das “ representações funcionais »}

- A concepção de novos dispositivos. Para conceber eficazmente novos dispositivos técnicos é indispensável, entre outras coisas, poder prever tanto quanto isso possa fazer-se, " a atividade futura possível » dos operadores que os deverão utilizar. Para isso é útil e necessário confrontar o conjunto das diferentes representações de todos os parceiros da empresa operadores, técnicos, concetores - e as dos ergónomos a fim de conseguir a formulação de propostas eficazes do ponto de vista do funcionamento das instalações e do respeito pelos modos de funcionamento humano [DANIELLOU (1985)].

Além disso a elaboração de diversas “ ajudas ao trabalho » deve basear-se na análise das representações dos utilizadores sob pena da sua inutilidade ou mesmo de incómodo na realização do trabalho [WEILL-FASSINA (1981)].

- A formação dos operadores. Neste domínio, as “ representações funcionais » dos operadores constituem a base a partir da qual a formação pode, e deverá, ser construída. Um operador em formação não é uma cabeça vazia a preencher, tanto mais quanto tem já uma certa idade 
e portanto uma certa experiência, ainda que essa seja limitada. O conhecimento destas

“ representações » é pois uma etapa prévia a qualquer transmissão de novas informações e uma condição da sua assimilação.

\section{Conclusão}

Para concluir muito brevemente citarei [LEPLAT (1985)] que se interroga sobre " o que seria preciso substituir no conceito de representação mental para poder dispensá-lo, e assim apreender a sua importância ?».

\section{BIBLIOGRAFIA}

Bainbridge, L. (1969). The nature of mental model in process control. Unpublished paper. Dept. of Psychology. Univ. of Reading. England.

Bisseret, A. (1970-1971). Mémoire opérationnelle et structure du travail. Bulletin de Psychologie, XXIV, 5-6, $\mathrm{N}^{\circ}$ 289, 280-294.

Carnino, A. et alii (1986). Les erreurs de représentation : pourquoi certaines peuvent être qualifiées de “ diaboliques ». Rapport GRETS-EDF, Paris.

Daniellou, F. (1985). La modélisation ergonomique de l'activité de travail dans la conception industrielle. Le cas des industries de processus continu. Thèse pour le Doctorat d'ergonomie. CNAM, Paris.

Dejours, C. et alii. (1988). Plaisir et souffrance dans le travail. Orsay, Éditions de l'AOCIP.

Leplat, J. (1985). Les représentations fonctionnelles dans le travail. In S.Ehrlich, Les représentations. Psychologie Française. Paris : A. Colin.

Neisser, U. (1967). Cognitive psychology. New York : Appleton-Century-Crofts.

Ochanine, D. (1969). Rôle de l'image opérative dans la saisie du contenu informationnel des signaux. Questions de psychologie, $\mathrm{n}^{\circ} 4$.

Ochanine, D. (1972). Déformation fonctionnelle des images opératives . Questions de psychologie, $\mathrm{n}^{\circ} 4$.

Ochanine, D. (1977). L'image opérative. Séminaire du Laboratoire de physiologie du travail Ergonomie, CNAM (non publié).

Pailhous, J. (1970). La représentation de l'espace urbain . L'exemple du chauffeur de taxi. Paris, PUF.

Piaget, J., \& Inhelder, B. (1966). L'image mentale chez l'enfant. Paris, PUF.

Richard, J-F. (1983). Logique de fonctionnement, logique d'utilisation. Rapport INRIA, nº 202, 47.

Savoyant, A. (1981). Image opérative et problèmes de coordination inter individuelle dans l'activité collective. In L'image opérative . Actes du séminaire du Département d'ergonomie et d'écologie humaine. Université Paris I. 82-90. 
Vermersch, P. (1981). Image opérative ou représentation fonctionnelle ? A propos de quelques difficultés sémantiques. L'image opérative. Actes du séminaire du Département d'ergonomie et d'écologie humaine. Université Paris I, 44-60.

Weill-Fassina, A. (1981). Image opérative ou représentation fonctionnelles ? Intérêt pour la conception et l'utilisation d'intermédiaires graphiques. L'image opérative. Actes du séminaire du Département d'ergonomie et d'écologie humaine. Université Paris I, 61-81.

Wisner, A., \& Daniellou, F.(1986). Vers uns technologie cerveau compatible. Actes du premier Congrès international sur le génie industriel AFCET-CEFI- XGi, 791-799. 